\title{
Toward a Polarimetric Radar Classification Scheme for Coalescence-Dominant Precipitation: Application to Complex Terrain
}

\author{
Leonardo Porcacchia, ${ }^{\mathrm{a}}$ P. E. Kirstetter, ${ }^{\mathrm{b}, \mathrm{c}}$ J. J. Gourley, ${ }^{\mathrm{c}}$ V. Maggioni, ${ }^{\mathrm{a}}$ B. L. CheOnG, ${ }^{\mathrm{b}}$ \\ AND M. N. ANAGNOSTOU ${ }^{\mathrm{d}}$ \\ ${ }^{a}$ Department of Civil Infrastructure and Environmental Engineering, George Mason University, Fairfax, Virginia \\ ${ }^{\mathrm{b}}$ Advanced Radar Research Center, National Weather Center, Norman, Oklahoma \\ ${ }^{\mathrm{c}}$ NOAA/National Severe Storms Laboratory, Norman, Oklahoma \\ ${ }^{\mathrm{d}}$ National Observatory of Athens, Athens, Greece
}

(Manuscript received 17 January 2017, in final form 24 August 2017)

\begin{abstract}
Accurate quantitative precipitation estimation over mountainous basins is of great importance because of their susceptibility to natural hazards. It is generally difficult to obtain reliable precipitation information over complex areas because of the scarce coverage of ground observations, the limited coverage from operational radar networks, and the high elevation of the study sites. Warm-rain processes have been observed in several flash flood events in complex terrain regions. While they lead to high rainfall rates from precipitation growth due to collision-coalescence of droplets in the cloud liquid layer, their characteristics are often difficult to identify. X-band mobile dual-polarization radars located in complex terrain areas provide fundamental information at high-resolution and at low atmospheric levels. This study analyzes a dataset collected in North Carolina during the 2014 Integrated Precipitation and Hydrology Experiment (IPHEx) field campaign over a mountainous basin where the NOAA/National Severe Storm Laboratory's X-band polarimetric radar (NOXP) was deployed. Polarimetric variables are used to isolate collision-coalescence microphysical processes. This work lays the basis for classification algorithms able to identify coalescence-dominant precipitation by merging the information coming from polarimetric radar measurements. The sensitivity of the proposed classification scheme is tested with different rainfall-rate retrieval algorithms and compared to rain gauge observations. Results show the inadequacy of rainfall estimates when coalescence identification is not taken into account. This work highlights the necessity of a correct classification of collision-coalescence processes, which can lead to improvements in quantitative precipitation estimation. Future studies will aim at generalizing this scheme by making use of spaceborne radar data.
\end{abstract}

\section{Introduction}

The frequency and intensity of extreme events have been increasing during the last decades worldwide (IPCC 2014). In particular, there is a statistically significant increase in heavy precipitation in more regions than where there is a decrease. Flash flooding represents the primary cause of weather-related fatalities, injuries, and damages in the United States (NOAA 2015). Weather-related hazards represent a threat particularly over complex terrain areas, characterized by inhomogeneous topography and pronounced orography. A high relief can be generally associated with the interaction with air masses forced upward and basins more prone to flooding with a faster concentration of

Corresponding author: Leonardo Porcacchia, 1porcacc@ gmu.edu streamflow and higher peak flows. The altitude and terrain steepness, together with the relative isolation of these regions, increase the risk connected with extreme events, making complex terrain regions vulnerable to floods, shallow landslides, and debris flows. In situ data to estimate precipitation rates are usually scarce. Remote sensing precipitation estimates by either ground-based or spaceborne sensors are valuable resources in complex terrain regions, even though they face challenges. The accuracy of satellite precipitation products is limited by their spatial and temporal resolution and depends strongly on rainfall variability (Ward et al. 2011; Derin and Yilmaz 2014; Kirstetter et al. 2015; Maggioni et al. 2016). Operational radars are affected by partial beam blockage due to the orography and by degradation of the signal at large distances from the antenna, leaving gaps in the radar network coverage (Maddox et al. 2002; Zhang et al. 2012, 2014). 
Orography has a strong influence on the development of precipitation. Mountains and ridges drive mechanical lifting of air masses that favor supersaturation and consequent formation of droplets. From the interaction of the droplets promoted by the induced updrafts, microphysical processes responsible for precipitation growth develop (e.g., collision-coalescence; Stoelinga et al. 2013). The impact of orography on the precipitation drop size distribution (DSD) is particularly pronounced at low atmospheric levels. In the eastern foothills of the Massif Central in France, Zwiebel et al. (2016) show that the evolution of DSD parameters manifests a wide variability connected to the topographic gradient, especially close to the ground. Observations at low levels are essential in capturing the development of precipitation processes and provide reliable quantitative precipitation estimates (QPEs) over complex terrain. The works by Mei et al. (2014) and Derin et al. (2016) evaluate the performance of several satellite-based rainfall (SBR) products over mountainous basins: results show that, even with some improvements when QPE algorithms are corrected with gauge data, SBR products tend to underestimate high rainfall-rate events that are more likely to cause floods. Flash flood events are well documented in complex terrain regions (Warner et al. 2000), and they are often observed in conjunction with low-echo centroid (LEC) precipitation systems and tropical/warm-rain environments characterized by high moisture and weak instability at low levels (Baeck and Smith 1998; Petersen et al. 1999; Vitale and Ryan 2013; Gochis et al. 2015).

Warm-rain processes (e.g., collision-coalescence, evaporation, breakup, size sorting) include all the microphysical processes that take place either in a warm cloud or in the portion of a cloud at temperatures $>0{ }^{\circ} \mathrm{C}$. They are generally associated with high-intensity rainfall events (Hamada et al. 2015). Warm-rain processes are prevalent in marine clouds and account for more than $70 \%$ of the total rain amount over the tropics (Lau and $\mathrm{Wu}$ 2003). However, they can also occur at midlatitudes (Carr et al. 2017) in deep convective clouds and in mountainous regions, where warm moist air is lifted due to orography. A warm-rain DSD is skewed toward a larger concentration of small diameter particles, with respect to the DSD of precipitation derived from melting of frozen hydrometeors (Squires 1956). This results in lower values of radar reflectivity $Z$ for a given rain rate. With $Z$ being dependent on the sixth power of the drop diameter (in the Rayleigh limit of drops smaller than the radar wavelength), it is more sensitive to largediameter drops in the DSD than to high concentrations of smaller particles. When a cloud warm layer is dominated by coalescence, drop sizes increase toward the surface as the more massive falling drops collide with, and collect, smaller particles. Thus, $Z$ increases with decreasing height in the liquid layer and reaches a maximum near the surface (Xu et al. 2008). Consequently, $Z$ observed in complex terrain, where the height of the radar beam can be well above the surface because of terrain blockages at low-elevation angles, will underestimate the actual $Z$ at the ground.

Several attempts have been made in the literature to identify warm-rain precipitation and to develop classification algorithms inclusive of these processes. Assuming that warm rain is characterized by the absence of the ice phase, a first class of classification schemes utilizes information from either active (radar echo-top heights below the $0^{\circ} \mathrm{C}$ isotherm) or passive sensors (e.g., minimum infrared brightness temperature) on board satellite missions (Liu and Zipser 2009). This assumption is effective in tropical/oceanic clouds, but at higher latitudes a cloud can present both warm and cold phases; its vertical structure therefore has to be analyzed to infer microphysical processes. Xu et al. (2008) identify tropical precipitation based on the analysis of the groundbased Next Generation Weather Radar (NEXRAD) radar vertical profiles of reflectivity (VPR). The use of single-polarization radar data is the main limitation of this work.

To complement radar information, Grams et al. (2014) introduce environmental variables from a numerical weather prediction model analysis to identify conditions in which warm-rain processes are likely present. They are found to develop in conjunction with high $0^{\circ} \mathrm{C}$ isotherm height, high low-level relative humidity, and low midlevel lapse rates (approximately moist adiabatic). Based on these environmental variables, provided by the $20-\mathrm{km}$ resolution Rapid Update Cycle (RUC) model applied over the southeastern United States, a probability of enhanced rain rates by warm-rain processes is developed for the precipitation classification algorithm used in the National Severe Storm Laboratory (NSSL) Multi-Radar Multi-Sensor system (MRMS; Zhang et al. 2016) alongside the technique by Xu et al. (2008). Nevertheless, the applicability of this methodology to orographic terrain is limited by the complex interactions between orography and the low-level environment, which are not well represented by the RUC model.

An improved classification scheme for warm-rain precipitation, in particular coalescence-dominant, based on environmental properties and microphysics of precipitation is therefore germane. Dual-polarization radars are appropriate instruments to utilize in this endeavor since they provide essential information about the shape, orientation, concentration, and phase of hydrometeors (Zrnić and Ryzhkov 1999). A list of polarimetric hydrometeor classification algorithms developed using radar 
variables at $\mathrm{X}, \mathrm{C}$, and $\mathrm{S}$ bands is available in $\mathrm{Al}-\mathrm{Sakka}$ et al. (2013). The algorithms are effective in providing a snapshot of the hydrometeor distribution in the cloud at a given moment, but do not directly provide information about the microphysical processes taking place in such an environment or their vertical and temporal evolution. Kumjian et al. (2012) study the response at X band of polarimetric radar variables to several warm-rain processes; coalescence is found to increase the reflectivity factor at horizontal polarization $Z_{h}$ and the differential reflectivity $Z_{\mathrm{dr}}$ and, consequently, the rain rate at the ground. Similar findings are obtained with simulations at C and S bands (Kumjian and Prat 2014). Despite the great potential of polarimetry for precipitation classification, a specific algorithm to identify coalescence-dominant warm-rain processes in midlatitude precipitation systems is still missing. An attempt in this direction is presented by Carr et al. (2017), who propose a framework in which $Z_{h}, Z_{\mathrm{dr}}$, and specific differential phase $K_{\text {dp }}$ polarimetric variables from the S-band NEXRAD network are used to generate parameter spaces to discriminate between warm-rain (coalescence) and non-warmrain precipitation. Carr et al. (2017) focus on a dataset collected in the eastern and central United States, and the applicability of their findings to mountainous areas is assessed in the present study.

The work presented in this paper aims to improve radar QPEs in complex terrain regions. A new polarimetric procedure is proposed to identify collision-coalescence warm-rain processes ("coalescence processes" hereinafter) using retrievals from an X-band dual-polarization radar and ground observations from disdrometers and rain gauges. Section 2 describes in detail the Integrated Precipitation and Hydrology Experiment (IPHEx) dataset analyzed in this work and the polarimetric methodology proposed based on the polarimetric radar data parameter spaces. Results are shown in section 3, including a comparison between radar retrievals and ground observations. Section 4 draws the conclusions and introduces a few points warranting further research.

\section{Data and methodology}

Currently, the best way to obtain reliable data over mountainous regions at varying heights, specifically the lowest ones, is to use ground instruments in the framework of a field campaign to bypass natural obstacles from orography. X-band radars that operate at high frequencies ranging from 8 to $12 \mathrm{GHz}$ are suitable for field campaigns because they are equipped with relatively small antennas (approximately 1-2 $\mathrm{m}$ in diameter), making them portable. They provide high-resolution information on hydrometeors (particle size, shape, orientation) at several antenna elevations. Reflectivities $Z_{h}$ and $Z_{\mathrm{dr}}$ and cross-correlation coefficient $\rho_{\text {hv }}$ polarimetric variables are used to study the vertical evolution of microphysical processes in the atmosphere and to generate the Cao-Zhang $(\mathrm{CZ})$ and Kumjian-Prat (KP) parameter spaces (Zhang et al. 2006; Cao et al. 2008; Kumjian and Prat 2014). This analysis reveals the "fingerprints" of coalescence development in precipitation events. A schematic of the procedure adopted in this work is shown in Fig. 1 and will be referenced throughout the paper.

\section{a. IPHEx field campaign}

The 2014 IPHEx was designed as one of the ground validation field campaigns for NASA's Global Precipitation Measurement (GPM) mission (Barros et al. 2014; Hou et al. 2014). It aims at characterizing warmseason orographic precipitation regimes and hydrologic processes in complex terrain regions over the southern Appalachian Mountains in the United States. The IPHEx campaign consisted of two activities: 1 ) the extended observing period (EOP) from October 2013 through October 2014 and 2) the intensive observing period (IOP) from May to July 2014 following the launch of the GPM core observatory. This work analyzes a dataset collected during the IOP activity in the Pigeon River basin, North Carolina (Fig. 2), with the NOAA X-band polarimetric radar (NOXP). The NOXP radar was positioned at an elevation of $1176 \mathrm{~m}$ on a low ridge within the Pigeon River basin $\left(35.5642^{\circ} \mathrm{N}\right.$, $82.9112^{\circ} \mathrm{W}$ ) and collected data from 1 May to 16 June 2014. NOXP's primary characteristics are listed in Table 1. It was operated in vertical "bird bath" scans, plan position indicator (PPI), and range height indicator (RHI) modes, scanning the atmosphere at elevations varying from $0.1^{\circ}$ to $15.0^{\circ}$ (PPI) and from $0^{\circ}$ to $45^{\circ}$ (RHI). Range resolution is $150 \mathrm{~m}$ for PPIs and $70-80 \mathrm{~m}$ for RHIs. A network of 20 NASA ground stations including disdrometers [Parsivel and two-dimensional video disdrometer (2DVD)] and tipping-bucket rain gauges are also used for ground validation, as shown in the methodological framework in Fig. 1.

\section{b. SCOP-ME algorithm}

First, the $Z_{\mathrm{dr}}$ data from the NOXP radar are corrected for miscalibration using vertical bird-bath scans where the intrinsic value is known (i.e., $0 \mathrm{~dB}$ ). Furthermore, the data are compared to collocated 2DVD data operated and maintained by NASA. A drawback of high-frequency radars is the potential attenuation of the radar signal when encountering precipitation. The self-consistent with optimal parameterization attenuation correction and rain microphysics estimation algorithm (SCOP-ME; Anagnostou et al. 2013; Kalogiros et al. 2013, 2014) is applied to the 


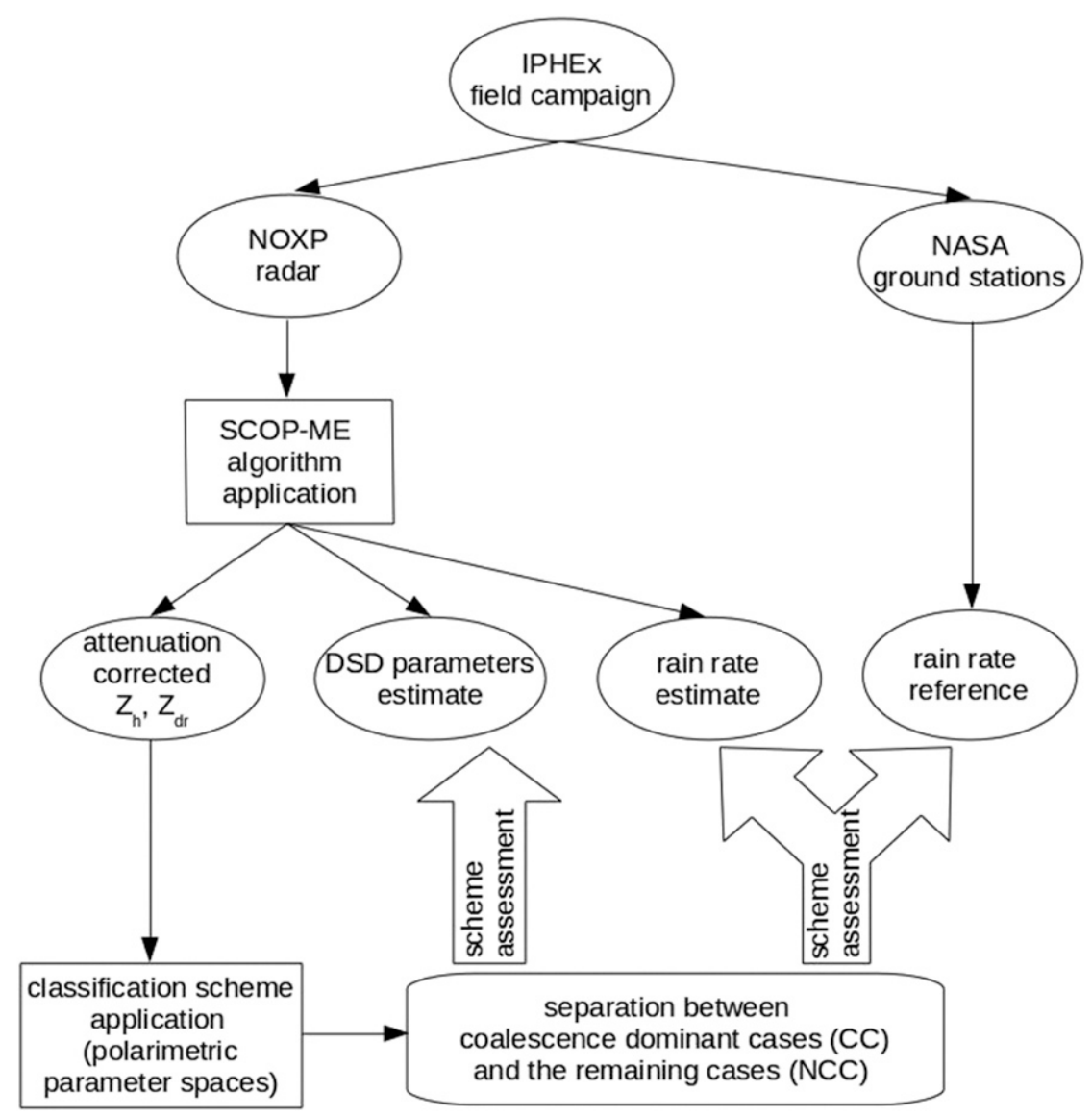

FIG. 1. Flowchart of the methodology adopted in this study.

radar dataset to overcome this issue. SCOP-ME provides attenuation correction at $\mathrm{X}$ band for $Z_{h}$ and $Z_{\mathrm{dr}}$ by estimating parameters for specific attenuation at horizontal polarization and differential attenuation. It also provides estimates of microphysical parameters and rainfall rate (Fig. 1).

SCOP-ME assumes the rain DSD to be described by a normalized gamma distribution (Illingworth and Blackman 2002):

$$
n(D)=N_{w} f(\mu)\left(\frac{D}{D_{0}}\right)^{\mu} \exp \left[-(\mu+3.67) \frac{D}{D_{0}}\right],
$$

where $n(D)\left(\mathrm{m}^{-3} \mathrm{~mm}^{-1}\right)$ is the number density, $N_{w}\left(\mathrm{~mm}^{-1} \mathrm{~m}^{-3}\right)$ is the intercept parameter, $D_{0}(\mathrm{~mm})$ is the median volume diameter, and $\mu$ (unitless) is the shape parameter. The function $f(\mu)$ is described as follows:

$$
f(\mu)=\frac{6}{3.67^{4}} \frac{(3.67+\mu)^{\mu+4}}{\Gamma(\mu+4)},
$$

where $\Gamma$ represents the gamma function, and $\mu$ is constrained as an exponential function of $D_{0}$, derived from 6 years of 2DVD disdrometer observations in Athens, Greece, from 2002 to 2009. The raindrop axis ratio is described by $r_{e}=1-(1-r) \beta_{e} / 0.066$, where $r$ is a fourth-degree polynomial of the drop diameter (Beard and Chuang 1987), and $\beta_{e}$ is the effective slope parameter that is allowed to oscillate between 0.026 and $0.106 \mathrm{~mm}^{-1}$. This expression aims to include deviations from Beard and Chuang's (1987) ratio model while keeping its shape fixed. The orientation angle of falling drops is described by a Fisher distribution with $7.5^{\circ}$ standard deviation (Bringi and Chandrasekar 2001). To consider the Mie character of scattering at X band, a multiplicative factor (a third-degree rational polynomial) is added to the right-hand side of the analytical expression of $D_{0}$ in the Rayleigh limit. The T matrix scattering simulations at $\mathrm{X}$ band are thus carried out varying $D_{0}$ and $N_{w}$ over a wide range of values [0.5 $\leq$ $D_{0} \leq 3.5 \mathrm{~mm} ; 1 \leq \log _{10}\left(N_{w}\right) \leq 5$ ], and the best fits for the DSD parameters and radar attenuation factors are obtained with a least squares method. Please note that the constrained $\mu$ assumption does not affect the estimated attenuation parameters. 


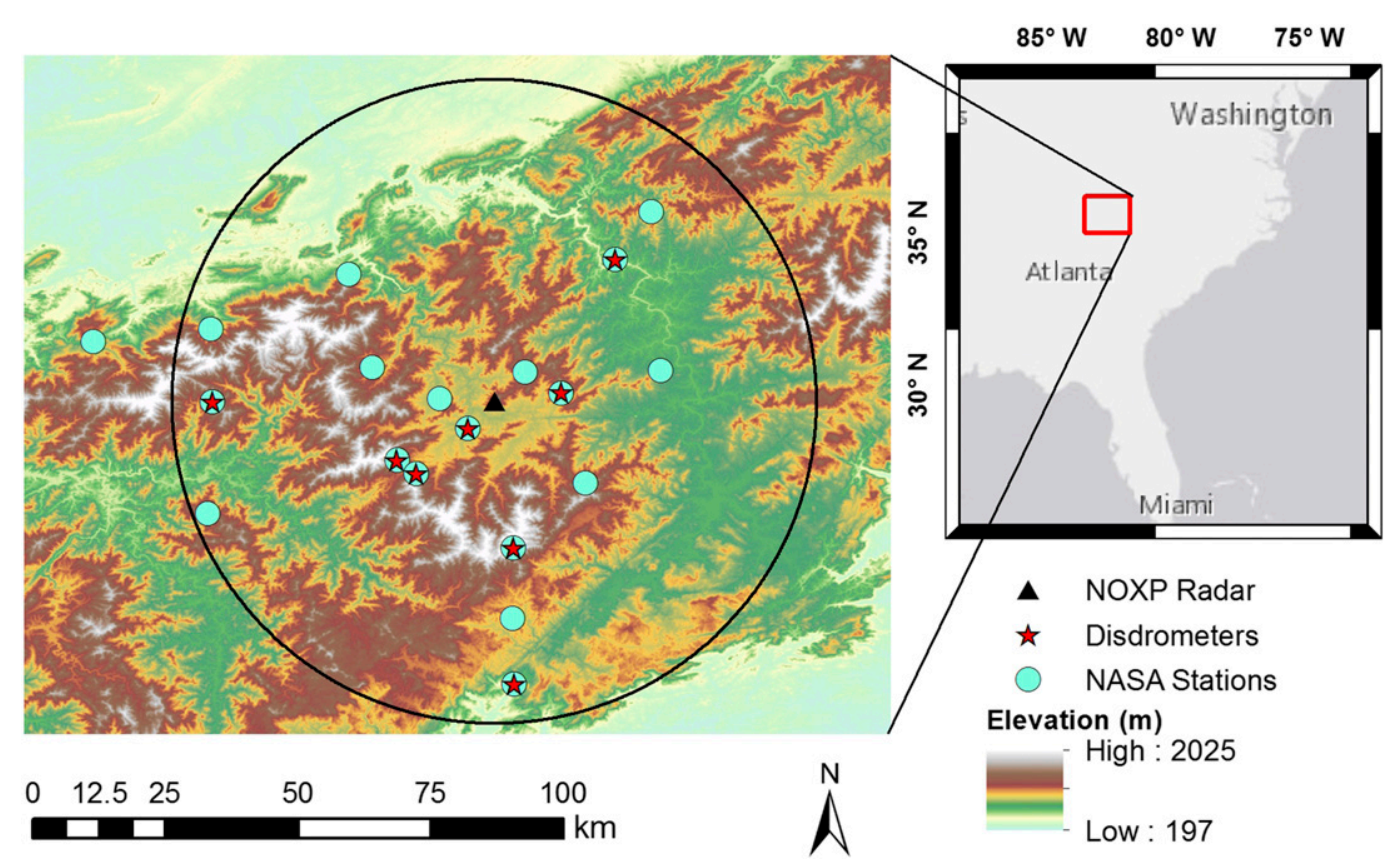

FIG. 2. Map of the IPHEx field campaign IOP phase (May-June 2014) deployment over the Pigeon River basin in the Appalachian Mountains, North Carolina. The black circle has a $60-\mathrm{km}$ radius and is centered at the location of the NOXP radar.

Kalogiros et al. (2013) perform a sensitivity analysis of the calculated parameters to the air temperature (varied between $5^{\circ}$ and $20^{\circ} \mathrm{C}$ ) and to a $15 \%$ random variability on the axis ratio. Results show very small errors and better performances compared to literature estimates of the same parameters. The effect of simulated typical calibration biases of $1 \mathrm{~dB} Z$ and $0.2 \mathrm{~dB}$ for $Z_{h}$ and $Z_{\mathrm{dr}}$, respectively, is to produce errors less than $20 \%$. Finally, the parameterization evaluation against disdrometer data shows a good agreement with correlation coefficients above 0.9 .

The performance of SCOP-ME is also evaluated using measurements from the National Observatory of Athens (NOA) high-resolution dual-polarization Doppler X-band radar (XPOL) and 2DVD disdrometers during 2008-11 in the urban area of Athens, Greece (Anagnostou et al. 2013).

TABLE 1. NOXP main characteristics.

\begin{tabular}{lc}
\hline \hline & NOXP \\
\hline Frequency $(\mathrm{GHz})$ & 9.40 \\
Peak antenna power (dBW) & 47 \\
Wavelength (cm) & 3.22 \\
Pulse repetition frequency (Hz) & 1350 \\
Polarization & Dual linear \\
Scan capabilities & PPI, RHI \\
Location & \\
$\quad$ Latitude & $35.5642^{\circ} \mathrm{N}$ \\
Longitude & $82.9112^{\circ} \mathrm{W}$ \\
Elevation (m MSL) & 1176 \\
\hline
\end{tabular}

The $Z_{h}$ and $Z_{\mathrm{dr}}$ corrected for rain attenuation show very good performance with low relative error compared to the same variables obtained from observed DSDs. The DSD parameters $D_{0}$ and $N_{w}$ are calculated with SCOPME parameterizations and with two other DSD retrieval algorithms: Park et al. (2005) and Gorgucci et al. (2008). SCOP-ME has lower relative error statistics when compared to the other estimates. Although for all three algorithms the estimate of $N_{w}$ is affected by noise or other factors (radar volume versus disdrometer point mismatch and spatial separation), the good estimate of $D_{0}$ with SCOP-ME reflects on the good statistics for rainfall rate that depends directly on $D_{0}$.

\section{c. Parameter spaces methodology}

This work proposes a new approach for identifying coalescence-enhanced precipitation events that takes advantage of polarimetric information provided by an $\mathrm{X}$-band dual-polarization radar. It is inspired by the Carr et al. (2017) methodology, which is based on the construction of polarimetric parameter spaces from $Z_{h}, Z_{\mathrm{dr}}$, and $K_{\mathrm{dp}}$. Here we use the $\mathrm{CZ}$ and $\mathrm{KP}$ parameter spaces, described below.

\section{1) CAO-ZHANG PARAMETER SPACE}

The radar variable $Z_{h}(\mathrm{dBZ})$ is used ubiquitously for meteorological investigations because it depends on the size, concentration, physical state, and shape of particles 

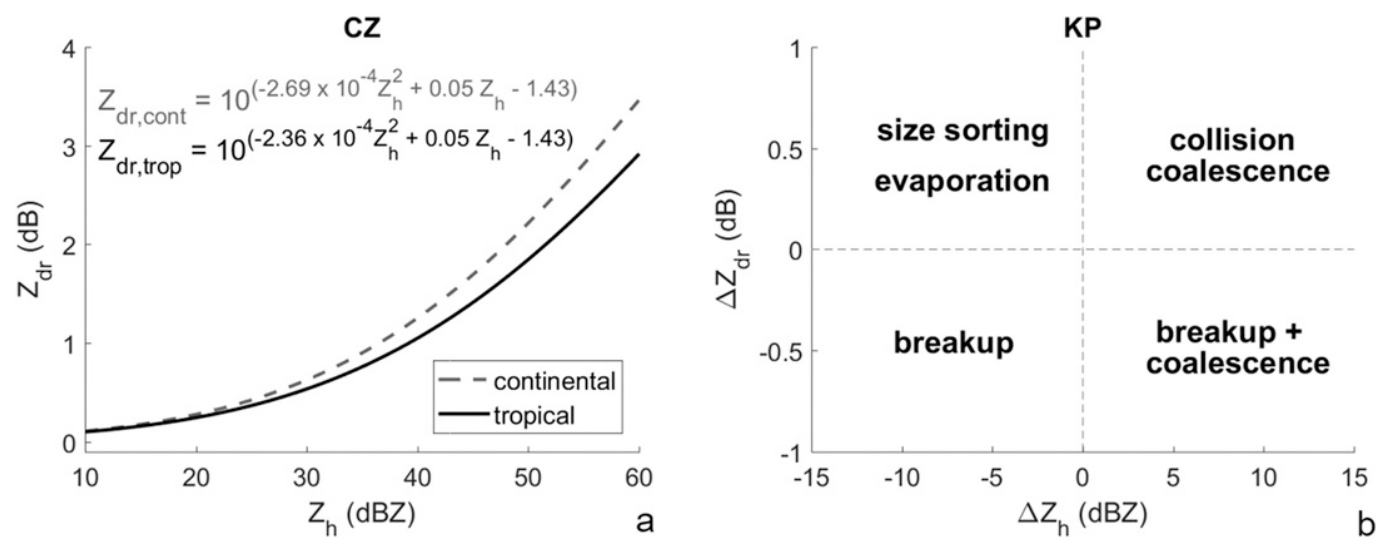

FIG. 3. (a) $\mathrm{CZ}$ parameter space, $Z_{h}$ vs $Z_{\mathrm{dr}}$ in the liquid layer. The continental and tropical curves are depicted. (b) KP parameter space, $\Delta Z_{h}$ vs $\Delta Z_{\mathrm{dr}}$, where the differences are taken between the bottom and the top of the liquid layer.

in the radar scattering volume. The variable $Z_{\mathrm{dr}}$ is defined as the difference between the reflectivity factors at horizontal and vertical polarization and is expressed in decibels. It provides valuable information about the size of raindrops and the spatial orientation of their maximum dimension, but it does not depend on their concentration. A scatterplot of $Z_{h}$ and $Z_{\mathrm{dr}}$ has been used by Ryzhkov et al. (2005) to give insight into the microphysical properties of precipitation and DSD. For a fixed value of $Z_{h}$, high values of $Z_{\mathrm{dr}}$ correspond to a DSD skewed toward bigger drops, while lower values of $Z_{\mathrm{dr}}$ are associated with dominance of smaller drops. Zhang et al. (2006) and Cao et al. (2008) attempt to quantify the dependence of $Z_{\mathrm{dr}}$ over $Z_{h}$ using datasets coming from different geographical regions. Zhang et al. (2006) produce a tropical dataset from scattering simulations at $\mathrm{S}$ band based on disdrometer observations in Florida and derive the following relation:

$$
Z_{\text {dr,tropical }}=10^{-2.362 \times 10^{-4} Z_{h}^{2}+0.0458 Z_{h}-1.433} \text {. }
$$

A similar function is retrieved by Cao et al. (2008) from 2DVD data collected in Oklahoma:

$$
Z_{\mathrm{dr}, \text { continental }}=10^{-2.686 \times 10^{-4} Z_{h}^{2}+0.0489 Z_{h}-1.429},
$$

labeled as continental curve $\left(Z_{h}\right.$ and $Z_{\mathrm{dr}}$ are in $\mathrm{dB} Z$ and $\mathrm{dB}$, respectively). Scatterplots of $Z_{h}$ and $Z_{\mathrm{dr}}$ compared to the continental curve have also been used to study precipitation characteristics of supercell hook echoes over the U.S. Great Plains and highlighted the presence of unusual tropical-like DSDs (Kumjian 2011; French et al. 2015). Figure 3 a shows the $Z_{h}-Z_{\mathrm{dr}}$ space with both the tropical and continental curves, named the CaoZhang parameter space. Warm-rain, and in particular coalescence-dominant precipitation, is expected to be characterized by the dominance of small drops in the DSD, namely, low values of $Z_{\mathrm{dr}}$ for a given $Z_{h}$. In the $\mathrm{CZ}$ space these drops are represented by points lying on or below the tropical curve. Note that the CZ curves result from fitting data derived by synthetic S-band scattering simulations; thus, real S-band observations are expected to show some variability along them. Moreover, the tropical curve is able to segregate warm rain in the $\mathrm{CZ}$ space at $\mathrm{X}$ band as well as at $\mathrm{S}$ band. The SCOP-ME algorithm addresses attenuation at $\mathrm{X}$ band, and the result of resonance scattering is to increase $Z_{\mathrm{dr}}$ values by a maximum of $1 \mathrm{~dB}$ in the interval $1-2.5 \mathrm{~dB}$ (Ryzhkov and Zrnić 2005). Using the mentioned tropical curve as a benchmark for X-band radar observations therefore has the effect of an even more conservative selection of events.

\section{2) KumJiAn-PRAT PARAMETER SPACE}

Kumjian et al. (2012) study the impact of several microphysical processes taking place in the cloud warm layer on polarimetric variables. Collision-coalescence is the most efficient warm process responsible for growth of drops, although other processes increase the median drop diameter of the DSD by separating bigger drops from small ones (size sorting) or completely removing very small drops from the precipitation distribution (evaporation). On the other hand, breakup tends to reduce the median drop diameter by depleting bigger drops from the DSD. Each one of these processes affects the vertical variation of radar variables in different ways. Specifically, $Z_{h}$ and $Z_{\mathrm{dr}}$ are increased by coalescence in the liquid layer, namely, between the brightband (BB) bottom (top of the liquid layer) and the surface. This work on polarimetric variables is formalized by Kumjian and Prat (2014), who identify fingerprints of collisional processes well distinguished from evaporation and 

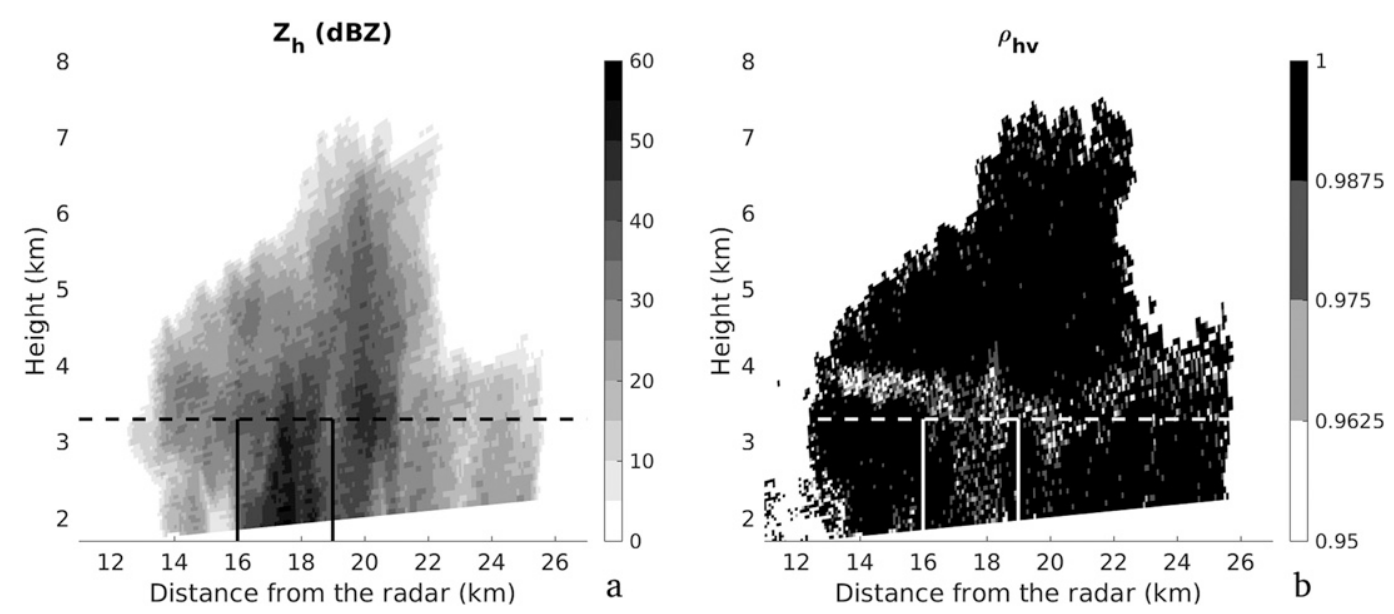

FIG. 4. RHI plots of (a) $Z_{h}$ and (b) $\rho_{\mathrm{hv}}$ at $264^{\circ}$ azimuth and 1845 UTC for the precipitation event of 26 May 2014. The horizontal dashed line approximates the height of the ML bottom, and the vertical lines intercept an interval of high reflectivity in the liquid layer.

size-sorting signatures at $\mathrm{C}, \mathrm{S}$, and $\mathrm{X}$ radar bands and plot the $\Delta Z_{h}-\Delta Z_{\mathrm{dr}}$ parameter space for the first time. The KP parameter space considers the vertical variation of $Z_{h}$ and $Z_{\mathrm{dr}}$ in the liquid layer: an increase in both variables with decreasing height below the BB bottom $\left(\Delta Z_{h}>0\right.$ and $\Delta Z_{\mathrm{dr}}>0$ ) is represented by data in the first quadrant (top right), where collision-coalescence is expected (Fig. 3b). Note also that calculation of the KP space, as opposed to $\mathrm{CZ}$, does not require an absolute calibration of $Z_{h}$ and $Z_{\mathrm{dr}}$ that may not be always available.

\section{d. Selection of events}

The search for coalescence signatures starts with the analysis of vertical profiles of polarimetric variables obtained from either PPIs or RHIs. The vertical profiles are built synthesizing data coming from several RHIs, or collecting data from all the PPIs at varying elevation angles, during a given precipitation event. We define an event as a meteorological system characterized by $Z_{h}>25 \mathrm{~dB} Z$, distance from the NOXP radar less than $60 \mathrm{~km}$, and duration between 20 and $60 \mathrm{~min}$. The $60-\mathrm{km}$-limit radius is selected in order to ensure coverage of the lower levels of the atmosphere, given our focus on the cloud liquid layer. The time window is established to monitor an independent cell or a limited portion of a precipitation system and attempts to minimize the impact of diverse precipitation processes within volume coverage patterns. Nonetheless, as it will be shown later, a mixture of precipitation types attributable to different microphysical processes can be detected within a single event. The cloud liquid layer where coalescence processes develop is then identified. Background information is provided by MRMS products indicating $0^{\circ} \mathrm{C}$ isotherm and $\mathrm{BB}$ heights at $1 \mathrm{~km} \times 1 \mathrm{~km}$ spatial and hourly temporal resolution. Refined identification is based on the $\rho_{\text {hv }}$ profile, which indicates the occurrence and height of the melting layer (ML). Decreasing $\rho_{\mathrm{hv}}$ is associated with the presence of mixed hydrometeors in the radar sampling volume: ice particles, melting hydrometeors, and liquid drops. The focus of this study is mainly on the cloud liquid layer where warm-rain processes develop. If an ML is detected, the VPR shows a corresponding enhancement in the BB region, whose depth does not usually exceed $0.5 \mathrm{~km}$. All data below the BB bottom are in the liquid phase and thus appropriate for this study. When the ML is not detected, information from the MRMS database is used to segregate the liquid part of the cloud.

Figure 4 shows an example RHI sampled on 26 May with $Z_{h}$ (Fig. 4a) and $\rho_{\text {hv }}$ (Fig. 4b). The dashed line approximates the height of the ML bottom. According to MRMS, the $0^{\circ} \mathrm{C}$ level height is approximately $4.2 \mathrm{~km}$, in accordance with the $\rho_{\mathrm{hv}}$ profile that assumes a value close to 1 everywhere but between 3 and $4.2 \mathrm{~km}$ (where it drops to $0.95-0.96$ ) corresponding to the ML. The area between the 16- and 19-km range indicates a cell with enhancement of reflectivity toward the surface.

Median profiles of $Z_{h}$ and $Z_{\mathrm{dr}}$ at vertical steps of $0.2 \mathrm{~km}$ are calculated from the data available for each event and are used to populate the KP parameter space. Median values of $Z_{h}$ and $Z_{\mathrm{dr}}$ for the whole liquid layer are also calculated and plotted in the $\mathrm{CZ}$ parameter space. A total of 42 precipitation events are selected from the IPHEx field campaign, consisting of 30 effective days of data collected with NOXP. Thirty-one of these events are classified as coalescencedominant, under the condition of median polarimetric variables resulting in points in the first quadrant in the 

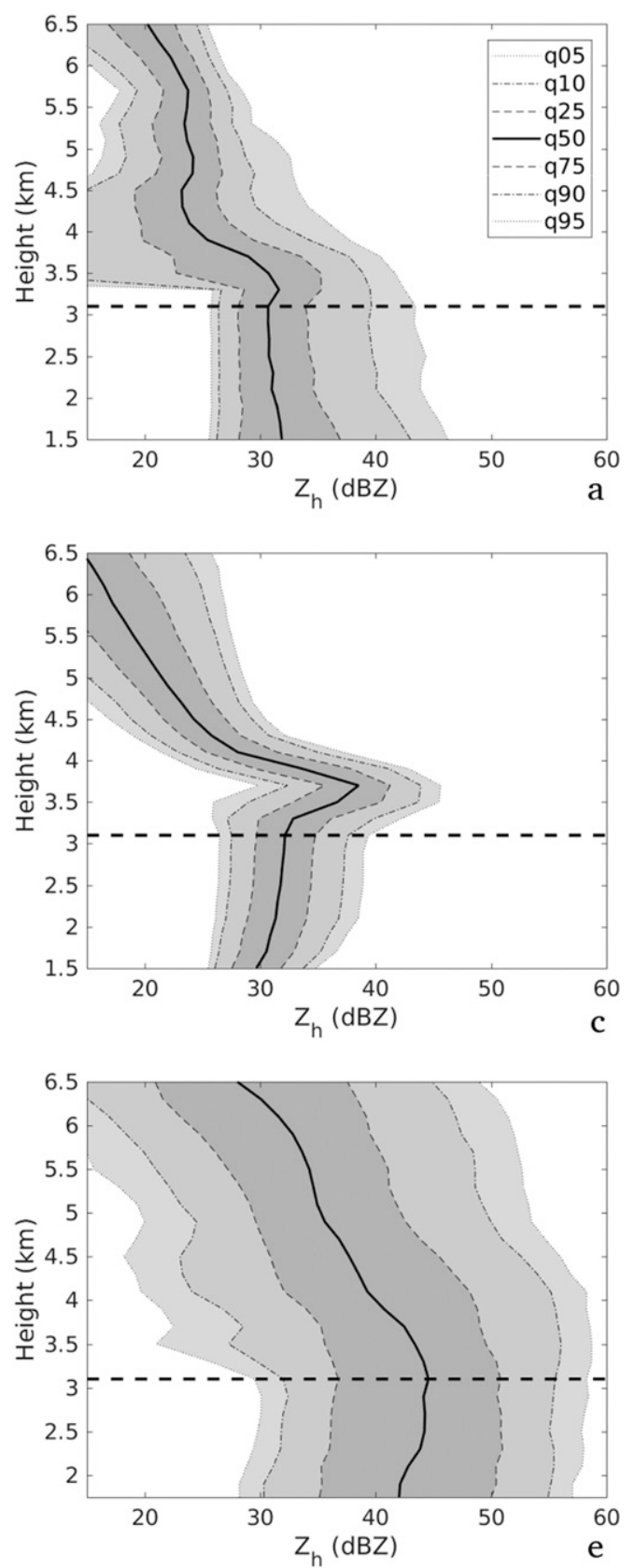
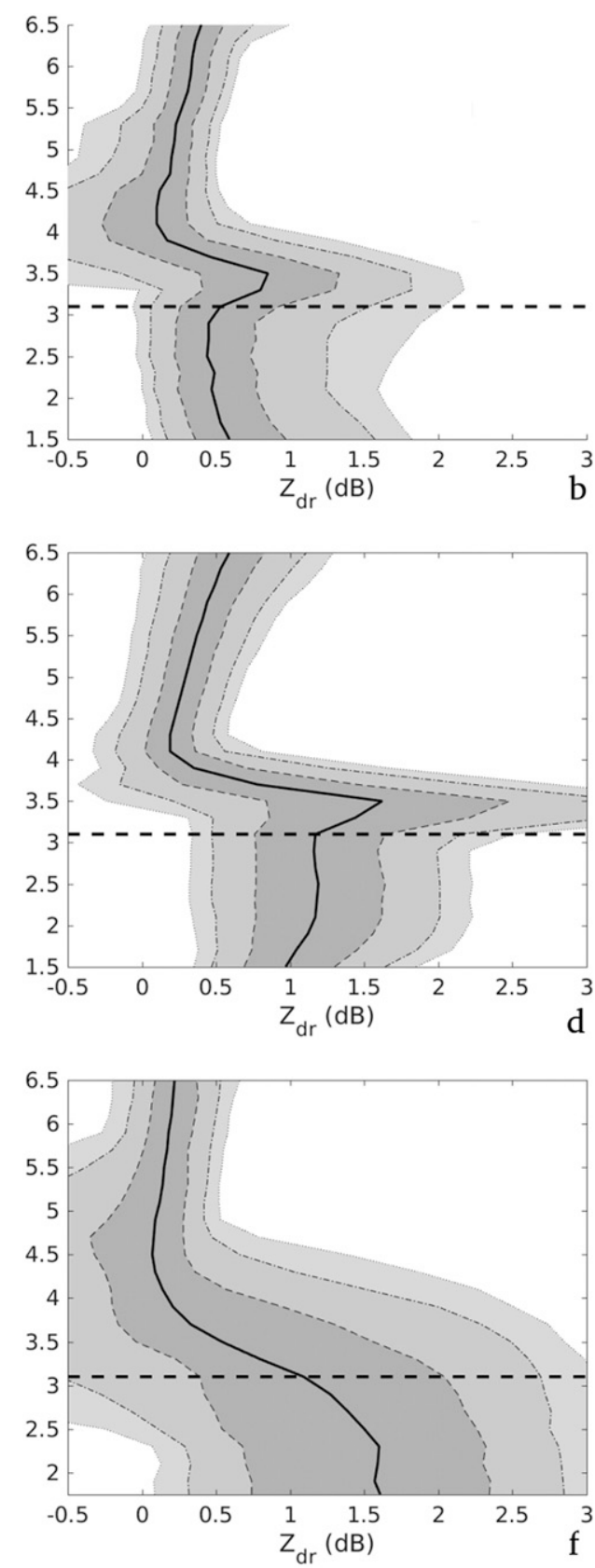

FIG. 5. Conditional quantile plots of vertical profiles of (left) $Z_{h}$ and (right) $Z_{\mathrm{dr}}$ for the precipitation events of (a),(b) 12 Jun, (c),(d) 27 May, and (e),(f) 28 May 2014. The horizontal dashed line represents the top of the liquid layer.

KP parameter space and below the tropical curve in the $\mathrm{CZ}$ parameter space. Please note that some of these events are just different time intervals of the same precipitation system measured at different locations within the $60-\mathrm{km}$ radius of NOXP. Eleven further cases are chosen for comparison purposes, with at least one of the two parameters spaces being inconsistent with warm-rain precipitation.
The proposed classification scheme for coalescence identification relies on the $\mathrm{CZ}$ and $\mathrm{KP}$ parameter spaces, and it has thus been applied using median values of $Z_{h}$ and $Z_{\mathrm{dr}}$ over an entire precipitation event. A further classification analysis is also performed (described in section 3a) based on the calculation of $\mathrm{CZ}$ and $\mathrm{KP}$ points at a higher-resolution grid in order to isolate single pixels in which coalescence takes place. The application 
of the classification scheme to the precipitation cases, in particular at the finer grid, is shown in the bottom-left block of Fig. 1.

\section{Results}

Three examples of precipitation events are selected adopting the parameter space methodology described in section $2 \mathrm{~d}$. The corresponding conditional quantile plots of vertical profiles of $Z_{h}$ and $Z_{\mathrm{dr}}$ are shown in Fig. 5: the first event on 12 June 2014 is classified as coalescencedominant (Figs. 5a,b), whereas the other two on 27 May 2014 (Figs. 5c,d) and 28 May 2014 (Figs. 5e,f) are classified as noncoalescence dominant. The dashed line represents the upper boundary of the cloud liquid layer. Pixels with reflectivity higher than $25 \mathrm{~dB} Z$ are selected in the liquid layer while no threshold is applied at higher heights; the intent here is to focus on a geographical region characterized by high-intensity precipitation and to remove the noise. The vertical averaged median value of $Z_{h}$ in the liquid layer for the coalescence case is approximately $30 \mathrm{~dB} Z$, with a large width resulting from the DSD breadth (which will be explored in the following paragraphs). In the second case, whose profile is typical of stratiform precipitation with a well-defined BB and $Z_{h}$ decreasing below it, the reflectivity is slightly lower, and its range of variation is much smaller. Parameter $Z_{h}$ is higher for the third case, with median values over $40 \mathrm{~dB} Z$ in the liquid layer and a peak of $45 \mathrm{dBZ}$ at its top, likely indicative of convection. Higher values of $Z_{h}$ are also evident in the cloud cold layer $\left(Z_{h}>30 \mathrm{~dB} Z\right)$ due to well-developed ice phase microphysical processes. These processes are partially noticeable in the coalescence case as well $\left(Z_{h} \sim 25 \mathrm{dBZ}\right.$ between 4.5 and $6 \mathrm{~km}$ ), suggesting the presence of frozen hydrometeors limited to the upper portion of the system that do not significantly deter collision-coalescence processes in the warm layer (Vitale and Ryan 2013). Higher median values of $Z_{\mathrm{dr}}$ correspond to larger and more oblate drops generated by melting of ice particles (stratiform case; Fig. 5d) and accretion processes (convective case; Fig. 5e). Collision-coalescence could be also responsible for the larger average values of $Z_{\mathrm{dr}}$ in Figs. $5 \mathrm{~d}$ and 5e. For a better understanding of the microphysical processes in the liquid layer, it is fundamental to investigate the vertical evolution of polarimetric variables.

The CZ parameter space provides the type of information described above, that is, a static view of the DSD to segregate the portion characterized by high concentration of small drops. It complements the information derived from the vertical profiles of $Z_{h}$ and $Z_{\mathrm{dr}}$, synthesized in the KP parameter space. The coalescence case differs from the others in terms of $Z_{h}$ and $Z_{\mathrm{dr}}$ slopes in the liquid layer. While in Figs. 5a and $5 \mathrm{~b}$, both variables slightly increase toward the surface because of collision-coalescence, in Figs. $5 \mathrm{c}$ and $5 \mathrm{~d}$ they decrease in accordance with breakup. The vertical gradient of the variables in the last case (Figs. 5e,f) suggests occurrence of size sorting-typical of deep convective storms-and evaporation (Kumjian and Ryzhkov 2010, 2012).

Figure 6 shows the conditional quantile plots of vertical profiles of $D_{0}$ and $N_{w}$ in the liquid layer, obtained from SCOP-ME simulations for the same three precipitation events. The slopes of the median profiles are also shown. The $D_{0}$ values for the 12 June 2014 event (Fig. 6a) are slightly smaller than $D_{0}$ values for the 27 May 2014 event (Fig. 6c), but $N_{w}$ values are approximately $4000 \mathrm{~mm}^{-1} \mathrm{~m}^{-3}$ higher (Figs. 6b,d). As a result of coalescence, mass from droplets that are available in high concentrations transfers to the bigger, scarcer drops (collectors). Therefore, the $D_{0}$ distribution widens because bigger drops have been created while droplets have not been completely depleted (Fig. 6a). In the stratiform case (Fig. 6c), evaporation depletes efficiently the smallest drops with a narrowing effect on the $D_{0}$ distribution below the bottom of the cloud $(\sim 2 \mathrm{~km})$, and breakup redistributes the mass of bigger particles into a number of smaller ones. The event on 28 May 2014 manifests the highest DSD breadth as a consequence of convection and mixing of liquid, melting, and frozen hydrometeors. In the liquid layer, particle diameters vary in a 2-mm (or larger) interval and diverse drop concentrations are found (Figs. 6e,f). A closer examination of the vertical variation of $D_{0}$ is warranted: for the coalescence event the median drop diameter increases in the liquid layer toward the surface (negative slope), while for the stratiform event it decreases, which is consistent with breakup. In the convective case the median drop diameter decreasing rate is more than double compared to the stratiform case, but the higher quantiles of the dimensional distribution increase, as a consequence of size sorting, which segregates bigger drops to the lower portion of the column.

\section{a. Fine-scale analysis}

The parameter space methodology is applied at a finer scale to infer the spatial distribution of precipitation for each event and segregate the pixels with coalescence signatures. PPI and RHI datasets are segmented in a horizontal grid of resolution $0.5 \mathrm{~km}$ in distance from NOXP and $1^{\circ}$ in azimuth. At $30-\mathrm{km}$ distance from NOXP (the average distance of the analyzed pixels), $1^{\circ}$ in azimuth corresponds to an arc of approximately $0.5 \mathrm{~km}$, the same resolution adopted in range. Vertically, 

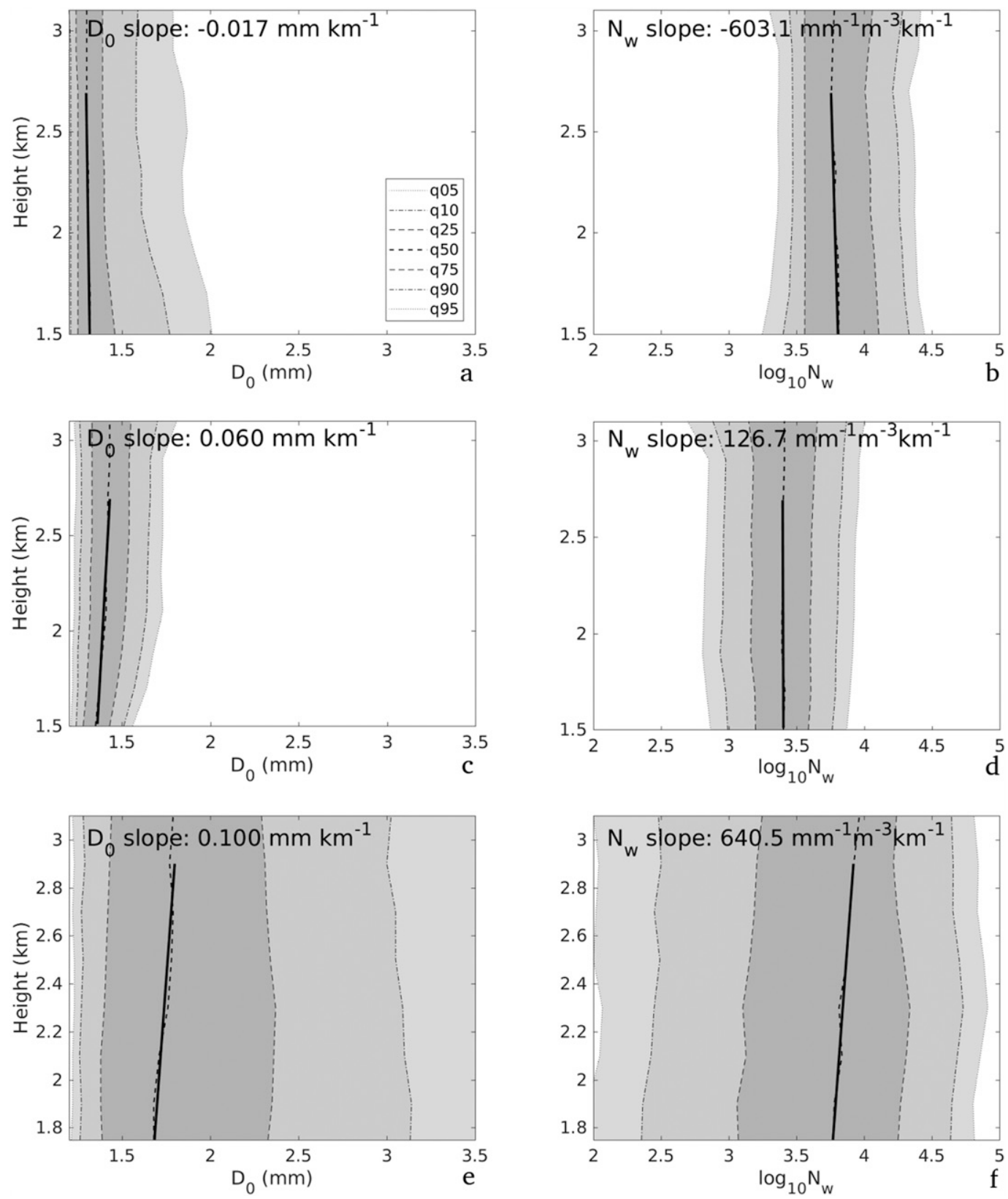

FIG. 6. As in Fig. 5, but for vertical profiles of DSD parameters (left) $D_{0}$ and (right) $N_{w}$ in the liquid layer only. Bold lines represent linear fits of $D_{0}$ and $N_{w}$, with positive sign if they increase from the bottom to the top of the liquid layer.

0.2-km intervals are used to calculate variable profiles. Temporally, the resolution is increased to the duration of a complete volume scan $(\sim 5 \mathrm{~min})$ for PPIs and to the duration of a single RHI (less than $1 \mathrm{~min}$ ) for events obtained from RHIs. Polarimetric variables are thus calculated as an average over the pixels (with $Z_{h}>$ $25 \mathrm{dBZ}$ ) falling in the same spatial 3D interval of $0.5 \mathrm{~km} \times 1^{\circ} \times 0.2 \mathrm{~km}$ in the resolution time. When at least two values of $Z_{h}$ and $Z_{\mathrm{dr}}$ at different heights on the vertical of the same grid point are calculated within the liquid layer, points in both $\mathrm{CZ}$ and KP parameter spaces can be calculated, and they become part of the finescale dataset.

Figures $7 \mathrm{a}$ and $7 \mathrm{~b}$ show the $\mathrm{CZ}$ and $\mathrm{KP}$ density scatterplots from the finescale dataset, respectively. In the KP space points are distributed across the four different quadrants, with a higher density in the first quadrant representing collision-coalescence in the liquid layer. 

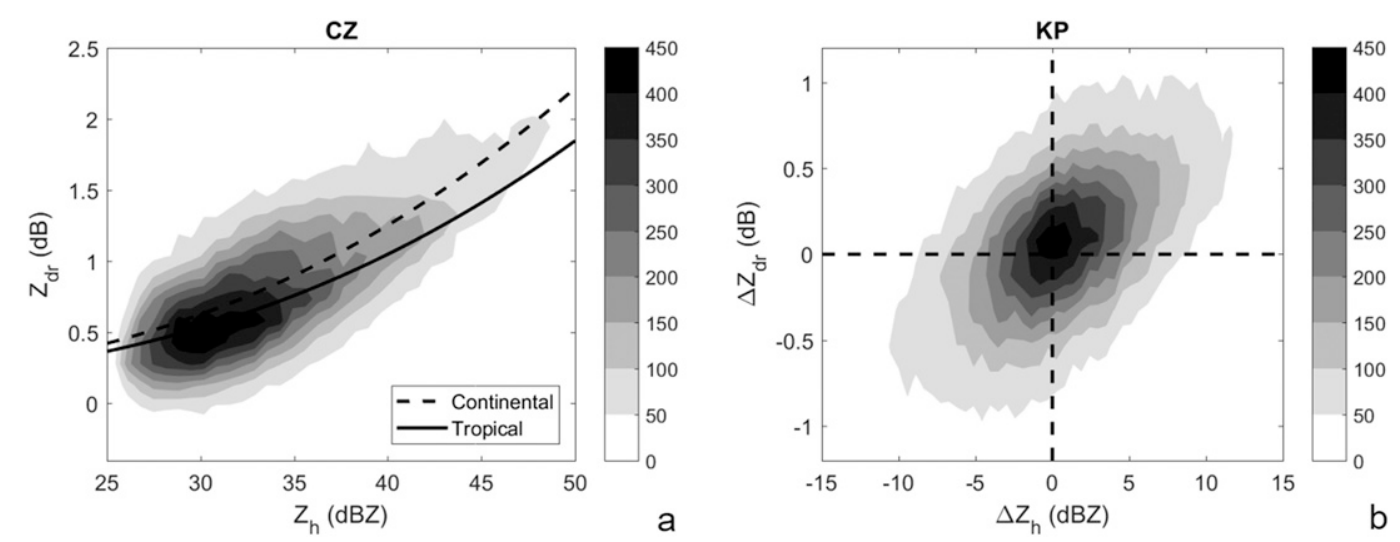

FIG. 7. (a) CZ and (b) KP contour plots for the finescale dataset.

This is consistent with the selection of the 42 cases, the majority of which show coalescence signatures. The same applies to the $\mathrm{CZ}$ space characterized by a bulk of points below the tropical curve between 28 and $34 \mathrm{dBZ}$. The $Z_{h}$ values range from 25 to $50 \mathrm{~dB} Z$. The upper limit with signature above the tropical curve is probably related to thunderstorm cores and strong convection (Zhang et al. 2006). These scatter density plots show evidence of diverse microphysical processes and drop sizes coexisting in the liquid layer of the selected dataset. Coalescence occurrences are identified when combining the information from the $\mathrm{CZ}$ and $\mathrm{KP}$ parameter spaces. Out of a total of 48418 points, $8555(\sim 18 \%)$ are classified as collision-coalescence (CC) dominant by meeting both conditions, that is, points belonging to the first quadrant of the KP space and below the tropical curve in the $\mathrm{CZ}$ space. The remaining 39863 points are labeled as noncoalescence (NCC) and are used for comparison (bottom-right block of Fig. 1).

An example of application of the classification scheme to a precipitation event is shown in Fig. 8. High reflectivity systems (up to $60 \mathrm{~dB} Z$ ) were monitored over the Pigeon River basin during the night of 14 May 2014 and day of 15 May 2014. The features of a mesoscale convective system (MCS) can be recognized in $Z_{h}$ PPIs taken in the morning of 15 May 2014, with convective cells developing along a line and a wider trailing stratiform region with lower reflectivity values. Figure 8 focuses on a specific time interval of the MCS observed by an NOXP volume scan taken between 0620 and 0625 UTC (Figs. 8a-c), and Fig. 8d shows a $Z_{h}$ PPI observed at $3.1^{\circ}$ elevation and at 0621 UTC. The analysis is confined to the interval of $200^{\circ}-290^{\circ}$ azimuth and $5-40-\mathrm{km}$ range from NOXP. In this region there are five ground stations providing measurements. The classification scheme is applied to identify coalescencedominant precipitation points within the spatial interval during a single volume scan. Figure 8 a shows the KP parameter space, highlighting in orange the points in the first quadrant. In Fig. 8b the same data are visualized in the $\mathrm{CZ}$ parameter space, with points in red meeting both $\mathrm{KP}$ and $\mathrm{CZ}$ coalescence conditions and thus labeled CC. A spatial distribution of these points is shown in Fig. 8c. The points meeting the $25-\mathrm{dBZ}$ threshold criterion, but without enough information to calculate the $\mathrm{CZ}$ and $\mathrm{KP}$ points, are indicated in aqua. As the KP parameter space point calculation requires at least two PPIs below the melting layer for computation, it is more demanding than the $\mathrm{CZ}$ parameter space that only requires one. $\mathrm{CZ}$ points are therefore calculated more frequently. A comparison between the coalescence classification (Fig. 8c) and the $Z_{h}$ PPI (Fig. 8d) indicates that points identified as CC do not necessarily correspond to the highest reflectivity pixels, in which convection most probably takes place.

The mean, median, and standard deviation (sigma) of the distributions of the DSD parameters $D_{0}$ and $N_{w}$ for $\mathrm{CC}$ and NCC points are presented in Table 2. The mean and median values of $D_{0}$ for the CC distribution are smaller than the corresponding values for the NCC distribution, while the $N_{w}$ values are greater. Results in Table 2 are thus consistent with a higher concentration of smaller particles for the $\mathrm{CC}$ case, in accordance with coalescence classification. The frequency histograms of the simulated parameters $D_{0}$ and $N_{w}$ are shown in Figs. 9a and 9b. For both $D_{0}$ and $N_{w}$ parameters, the Kolmogorov-Smirnov (KS) test rejects the hypothesis that CC and NCC points belong to the same distribution, with significance value less than 0.001 . For $N_{w}$ the separation between CC and NCC is more evident. The SCOP-ME algorithm does not have any specific parameterization for coalescence-dominant precipitation, although it shows a separation in the DSD between the $\mathrm{CC}$ and NCC points selected with the parameter spaces criterion, and therefore corroborates the validity of the 

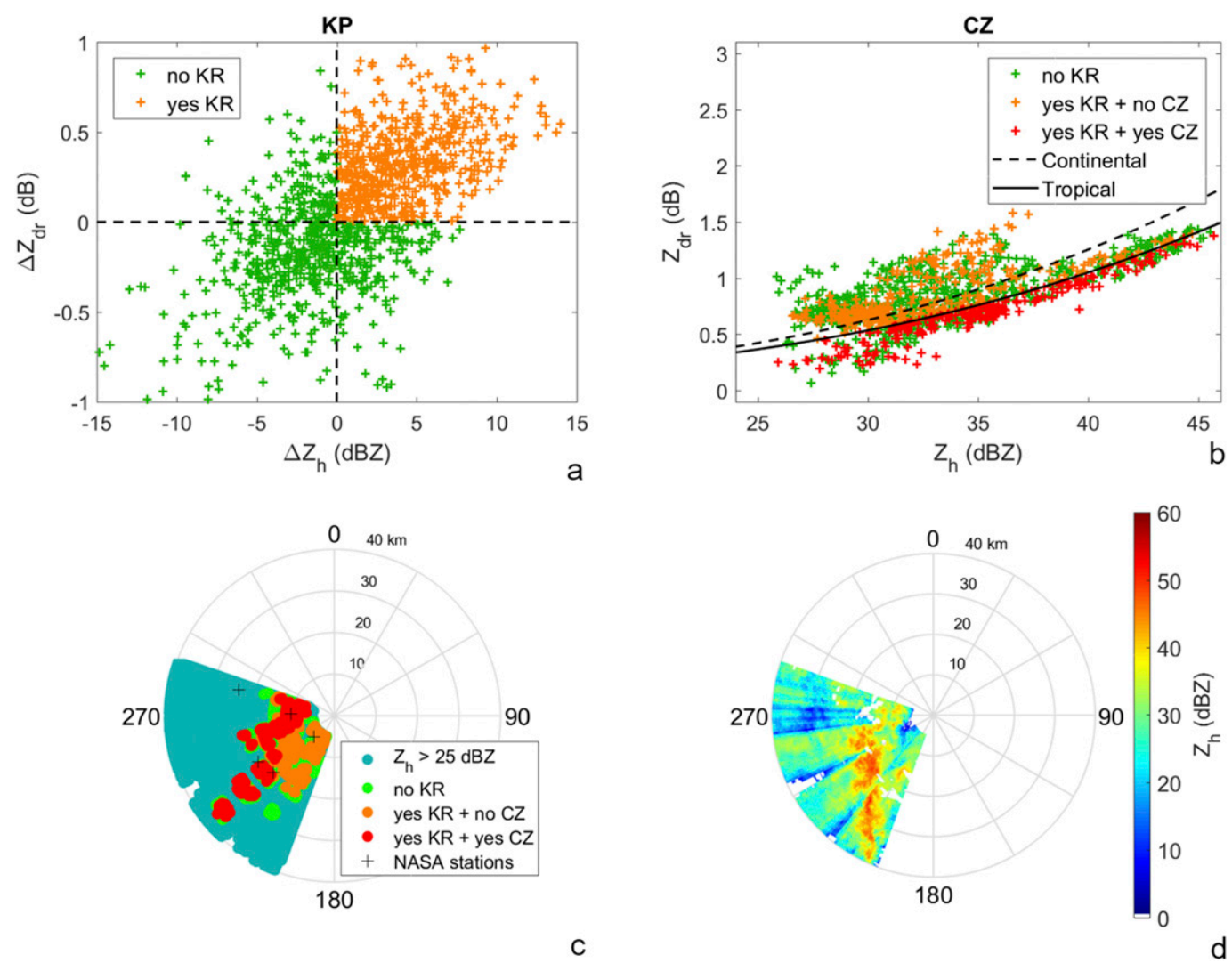

FIG. 8. Single volume scan relative to the precipitation event of 15 May 2014 (0620-0625 UTC). (a) KP and (b) CZ scatterplots. (c) Coalescence classification polar plot confined to 5-40-km ranges and $200^{\circ}-290^{\circ}$ azimuths. Aqua points indicate $Z_{h}>25 \mathrm{dBZ}$ but not enough information to calculate both parameter spaces; KP and CZ spaces are instead calculated for the green points. Orange points indicate KP alone consistent with coalescence, while red points have both $\mathrm{CZ}$ and $\mathrm{KP}$ in accordance with coalescence-dominant precipitation (CC points). (d) $Z_{h}$ PPI at $3.1^{\circ}$ antenna elevation and 0621 UTC for the same spatial interval.

classification scheme (Fig. 1). The next section addresses how the differing DSDs for CC and NCC points impact the calculated rainfall rates.

\section{b. Sensitivity analysis}

In this section the sensitivity of the proposed classification scheme to the typology of precipitation used for rainfall-rate estimation is tested. Rainfall rates are computed by the SCOP-ME algorithm according to the following equation:

$$
R=0.8106 F_{R}(\mu) N_{w} D_{0}^{4.67} f_{\mathrm{R} 2}\left(D_{0}\right),
$$

TABLE 2. SCOP-ME estimated DSD parameters $D_{0}$ and $N_{w}$.

\begin{tabular}{llcrr}
\hline \hline & & Mean & Median & Sigma \\
\hline$D_{0}(\mathrm{~mm})$ & CC & 1.46 & 1.37 & 0.27 \\
& NCC & 1.52 & 1.41 & 0.45 \\
$N_{w}\left(\mathrm{~mm}^{-1} \mathrm{~m}^{-3}\right)$ & CC & 12354 & 10201 & 9770 \\
& NCC & 8133 & 5769 & 7700 \\
\hline
\end{tabular}

where $F_{R}(\mu)$ is a function of $\mu$ and $f_{\mathrm{R} 2}\left(D_{0}\right)$ accounts for the exponential law, which relates the terminal velocity of raindrops to their diameter (Bringi and Chandrasekar 2001). The calculated rainfall-rate distributions for CC and NCC points are shown in Fig. 10a. The KS test once again rejects the hypothesis that the two distributions belong to the same parent one. SCOP-ME prescribes higher rainfall-rate values for CC points, as expected for coalescence-dominant precipitation.

Three standard $Z-R$ relationships (stratiform, convective, and tropical) of the form $Z=A R^{b}$ are also used for precipitation estimation. The values of the parameters $A$ and $b$ are presented in Table 3 . The rainfall-rate frequency distributions when the $Z-R$ relationships are applied are shown in Figs. 10b-d. The KS test still rejects the hypothesis that the CC and NCC distributions belong to the same population for all $Z-R$ relationships, but with lower significance compared to the SCOP-ME retrievals. The CC and NCC distributions are more overlapping in Figs. 10b-d compared to 

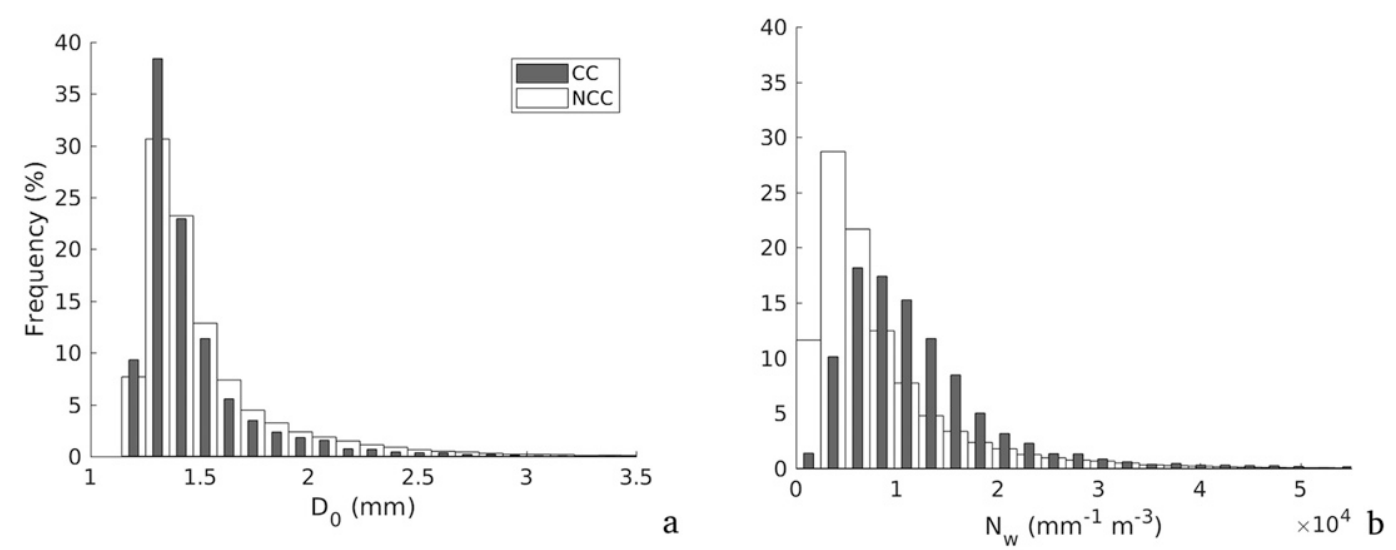

FIG. 9. Frequency distributions of DSD parameters (a) $D_{0}$ and (b) $N_{w}$ estimated from SCOP-ME for CC and NCC cases. CC indicates coalescence-classified points while NCC refers to points for which the CZ and KP parameters are not consistent with coalescence-dominant precipitation.

Fig. 10a. Statistics of the calculated distributions are presented in Table 4. Mean and median values are significantly higher for $\mathrm{CC}$ rainfall rates calculated by SCOP-ME compared to NCC retrievals. Such a difference becomes lower when the $Z-R$ relationships are applied, indicating that they are not able to correctly separate CC from NCC points. Furthermore, when the tropical $Z-R$ relationship is applied, the $\mathrm{CC}$ and $\mathrm{NCC}$
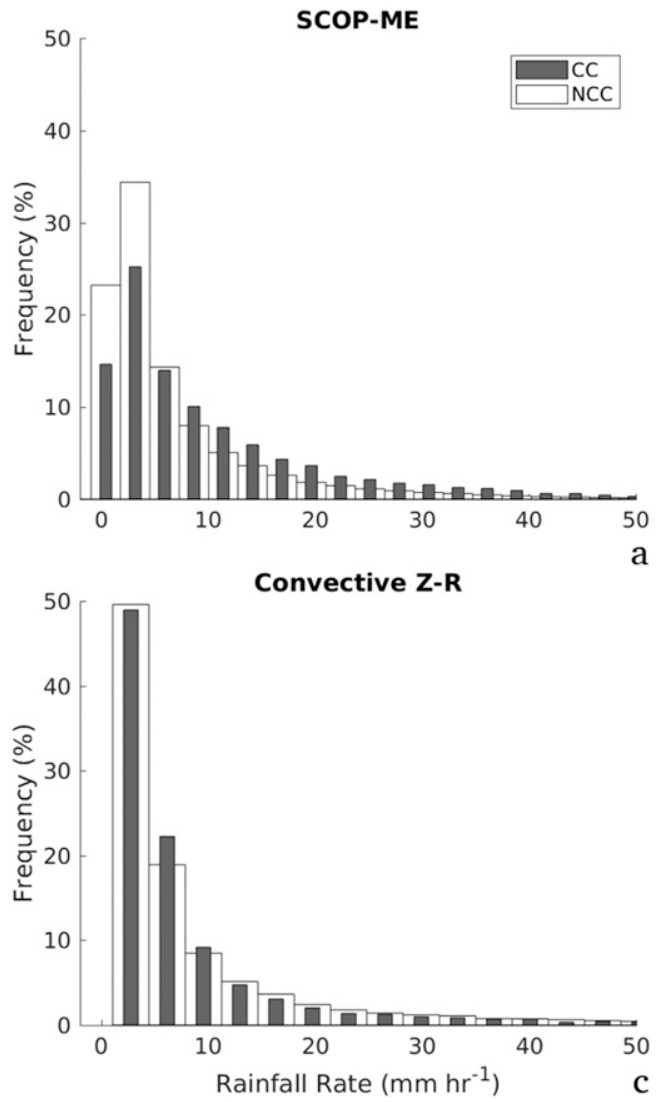

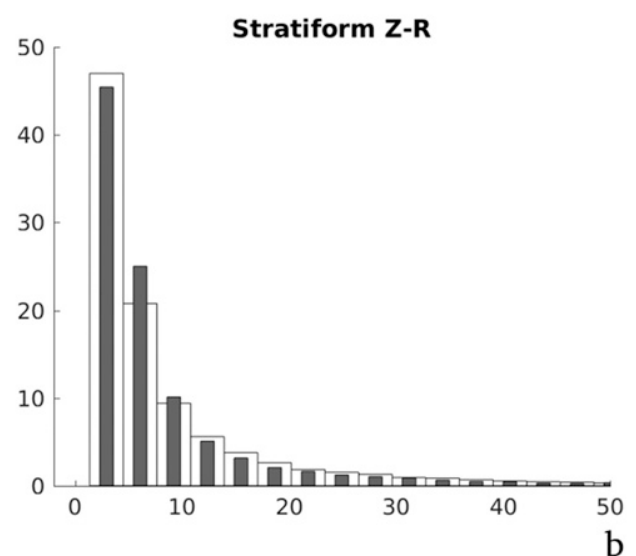

Tropical Z-R

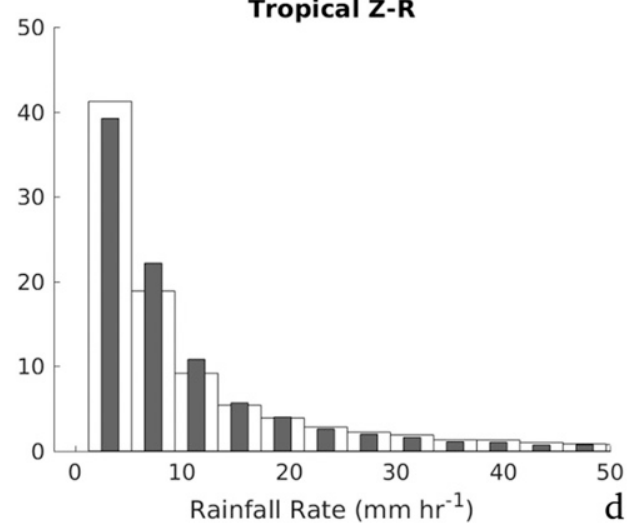

FIG. 10. Rainfall-rate frequency distributions for CC and NCC points when (a) the SCOP-ME algorithm, (b) a stratiform $Z-R$ relationship, (c) a convective $Z-R$ relationship, and (d) a tropical $Z-R$ relationship are used for precipitation retrieval. 
TABLE 3. Typical $Z-R$ relationships parameters.

\begin{tabular}{cccc}
\hline \hline & Stratiform & Convective & Tropical \\
\hline$A$ & 200 & 300 & 250 \\
$B$ & 1.6 & 1.4 & 1.2 \\
\hline
\end{tabular}

distributions widen (sigma values of 43.16 and $41.92 \mathrm{~mm} \mathrm{~h}^{-1}$, respectively) and prescribe unlikely high precipitation values.

Finally, an indirect assessment of the proposed classification scheme is performed through the comparison of radar-estimated precipitation rates with rain gauge data (bottom-right block of Fig. 1). Comparing radar and gauge (or disdrometer) data is not straightforward because of the difference in spatial and temporal resolution between the two data sources. Such comparison is performed by only considering retrievals from PPIs that encompass larger geographic areas over the gauges. Ground stations provide information at 1-min temporal resolution and at a specific location (with a poor spatial coverage). The accumulation time of precipitation is shown to be linked to the area of representativeness of measurements (Lebel et al. 1987). Therefore, temporal and spatial resolutions of precipitation measurements ( $\Delta t$ and $\Delta r$, respectively) are correlated. Berne et al. (2004) quantify the relation between $\Delta t$ and $\Delta r$ required for urban hydrology as

$$
\Delta r=\alpha \sqrt{\Delta t}
$$

where $\Delta t$ is in minutes, $\Delta r$ is in kilometers, and $\alpha=1.5 \mathrm{~km} \mathrm{~min}^{-1 / 2}$. Using this formula, a 5-min time resolution (duration of a volume scan) corresponds to $\Delta r=3.35 \mathrm{~km}$. To mitigate the measurement noise in the comparison, rainfall rates from gauges are accumulated over $\Delta t=10 \mathrm{~min}$ time intervals corresponding to spatial resolution intervals $\Delta r=4.74 \mathrm{~km}$. Radar data are averaged over $4.74 \mathrm{~km} \times 4.74 \mathrm{~km}$ boxes centered at the gauge locations and over two consecutive volume scans. Over the 20 NASA stations equipped with tippingbucket rain gauges, 19 stations located within a $60-\mathrm{km}$ radius of NOXP are used. Thirty-five significant cases are identified, matching radar retrievals with gauge observations, and 11 of them are $\mathrm{CC}$ according to the
TABLE 4. Rainfall-rate estimates $\left(\mathrm{mm} \mathrm{h}^{-1}\right)$ from radar measurements.

\begin{tabular}{llrcr}
\hline & & Mean & Median & Sigma \\
\hline SCOP-ME & CC & 10.64 & 6.51 & 11.49 \\
Stratiform $Z-R$ & NCC & 6.92 & 3.62 & 8.73 \\
& CC & 8.83 & 4.86 & 12.31 \\
Convective $Z-R$ & NCC & 9.30 & 4.80 & 12.43 \\
& CC & 9.84 & 4.56 & 17.03 \\
Tropical $Z-R$ & NCC & 10.45 & 4.50 & 16.92 \\
& CC & 19.25 & 6.83 & 43.16 \\
& NCC & 20.59 & 6.72 & 41.92 \\
\hline
\end{tabular}

proposed classification scheme. Radar rainfall rates are evaluated using SCOP-ME retrievals and the aforementioned $Z-R$ relationships. Rainfall-rate relative bias distributions are calculated as differences between radar and gauge rainfall rates divided by the gauge rates (rainfall "truth"). Mean values of the relative bias are presented in Table 5. A negative bias indicates radar underestimation, while a positive bias indicates overestimation. Overall, SCOP-ME shows the best performance in estimating rain rates; the mean biases for $\mathrm{CC}$ and NCC populations are both lower than $20 \%$ and similar in magnitude. Contrarily, when the $Z-R$ relationships are used, the differences in the relative CC and NCC biases increase. The convective and stratiform $Z-R$ relationships yield large negative bias $(-47 \%$ and $-45 \%$, respectively) for CC cases, while their performance significantly improves for NCC cases. On the other hand, the tropical $Z-R$ relationship yields good performance for CC cases, but overestimates in the NCC cases (62\% overestimation). It is specifically designed to assign higher rain rates to given reflectivities in tropical rainfall compared to other relations. In conclusion, the more sophisticated SCOP-ME rainfall retrieval algorithm is able to detect variability in the DSD by making use of the dual-polarized radar information and to estimate rain rates accordingly. The poor performance of the $Z-R$ algorithms under different microphysical regimes confirms the ability of the proposed classification scheme to separate coalescence-enhanced precipitation from rainfall events better described by convective/stratiform microphysics (melting of frozen hydrometeors).

TABLE 5. Mean values of rainfall-rate relative bias.

\begin{tabular}{lccccr}
\hline \hline & & SCOP-ME & Stratiform $Z-R$ & Convective $Z-R$ & Tropical $Z-R$ \\
\hline Relative bias & CC & -0.15 & -0.45 & -0.47 & -0.17 \\
& NCC & 0.18 & -0.11 & -0.08 & 0.62 \\
\hline
\end{tabular}




\section{Conclusions}

This study proposes a new classification scheme for the identification of coalescence-dominant precipitation based on polarimetric information from an X-band dualpolarization radar. The May-June 2014 IPHEx field campaign in North Carolina provides the dataset for implementation and evaluation of this scheme. The SCOP-ME algorithm is applied to measurements taken by the NOXP radar. The $Z_{h}, Z_{\mathrm{dr}}$, and $\rho_{\mathrm{hv}}$ polarimetric variables are used to populate the Cao-Zhang and Kumjian-Prat parameter spaces, which provide insight into the precipitation DSD and the microphysical processes occurring in the liquid layer of a precipitation system. In case of collision-coalescence processes in the liquid layer, the median profiles of $Z_{h}$ and $Z_{\mathrm{dr}}$ show increasing trends toward the surface. The $D_{0}$ and $N_{w}$ parameters of the normalized gamma DSD show consistency with higher concentration of small drops compared to precipitation resulting from melting of hydrometeors.

The classification scheme is applied at finer resolution ( $0.5 \mathrm{~km}$ in range; $1^{\circ}$ in azimuth; $5 \mathrm{~min}$ in time) to identify coalescence processes in regions where they coexist with diverse microphysical processes. The finescale dataset is divided in collision-coalescence-dominant (CC) and noncoalescence (NCC) points according to the proposed classification scheme. A separation between $\mathrm{CC}$ and NCC cases is apparent in the DSD parameter distributions as well as the rainfall-rate distributions. The SCOP-ME algorithm succeeds in separating CC from NCC precipitation because of its ability in estimating DSD properties, and it prescribes higher rainfall rates to $\mathrm{CC}$ for a given reflectivity value as expected. Conversely, $Z-R$ relationships are not able to distinguish between the two populations and their application to the overall dataset results in a discrepancy in performance between CC and NCC cases. Unfortunately, the limited number of available NASA stations matching radar observations does not allow for a thorough assessment of the performance of the rainfall retrieval methods. Furthermore, a robust assessment of DSD moments from disdrometers was not possible because of the lack of sufficient radar and disdrometer-coincident measurements at the ground.

Results show the importance of correct identification of CC processes to correctly predict rainfall rates at the ground. To improve QPEs, it is fundamental to retrieve the precipitation DSD, to be able to discern between different types of precipitation, and to derive adequate rainfall rates. The proposed classification scheme is able to identify coalescence from the microphysical information provided by radar polarimetric variables.
Application of the scheme to dual-polarization radar measurements in different environments and at varying radar frequencies would give more insight into its performance. Collected datasets from field campaigns taken in Colorado, France, Italy, and Greece will be analyzed in future studies. This study lays the foundation for a wider work aimed at identifying CC precipitation worldwide using the knowledge acquired with X-band radar polarimetry in mountainous regions.

Acknowledgments. The authors thank the Hydrometeorology and Remote Sensing (HyDROS) Laboratory of the University of Oklahoma (OU, in particular Dr. Yang Hong), the NOAA National Severe Storm Laboratory (NSSL, for access to the dataset), and the OU Advanced Radar Research Group (ARRC) of Norman, OK. PhD candidate Juan Garzon provided assistance in editing Fig. 2. Finally, the authors thank the three anonymous reviewers for their constructive comments that resulted in an improved quality of the manuscript.

\section{REFERENCES}

Al-Sakka, H., A. A. Boumahmoud, B. Fradon, S. J. Frasier, and P. Tabary, 2013: A new fuzzy logic hydrometeor classification scheme applied to the French X-, C-, and S-band polarimetric radars. J. Appl. Meteor. Climatol., 52, 2328-2344, https:// doi.org/10.1175/JAMC-D-12-0236.1.

Anagnostou, M. N., J. Kalogiros, F. S. Marzano, E. N. Anagnostou, M. Montopoli, and E. Picciotti, 2013: Performance evaluation of a new dual-polarization microphysical algorithm based on long-term X-band radar and disdrometer observations. J. Hydrometeor., 14, 560-576, https://doi.org/10.1175/JHM-D12-057.1.

Baeck, M. L., and J. A. Smith, 1998: Rainfall estimation by the WSR88D for heavy rainfall events. Wea. Forecasting, 13, 416-436, https:// doi.org/10.1175/1520-0434(1998)013<0416:REBTWF>2.0.CO;2.

Barros, A., and Coauthors, 2014: NASA GPM-ground validation: Integrated Precipitation and Hydrology Experiment 2014. NASA Tech. Rep., 64 pp., https://doi.org/10.7924/ G8CC0XMR.

Beard, K. V., and C. Chuang, 1987: A new model for the equilibrium shape of raindrops. J. Atmos. Sci., 44, 1509-1524, https://doi.org/ 10.1175/1520-0469(1987)044<1509:ANMFTE > 2.0.CO;2.

Berne, A., G. Delrieu, J.-D. Creutin, and C. Obled, 2004: Temporal and spatial resolution of rainfall measurements required for urban hydrology. J. Hydrol., 299, 166-179, https://doi.org/ 10.1016/S0022-1694(04)00363-4.

Bringi, V. N., and V. Chandrasekar, 2001: Polarimetric Doppler Weather Radar. Cambridge University Press, $636 \mathrm{pp}$.

Cao, Q., G. Zhang, E. Brandes, T. Schuur, A. V. Ryzhkov, and K. Ikeda, 2008: Analysis of video disdrometer and polarimetric radar data to characterize rain microphysics in Oklahoma. J. Appl. Meteor. Climatol., 47, 2238-2255, https:// doi.org/10.1175/2008JAMC1732.1.

Carr, N., P. E. Kirstetter, J. J. Gourley, and Y. Hong, 2017: Polarimetric signatures of midlatitude warm-rain precipitation events. J. Appl. Meteor. Climatol., 56, 697-711, https://doi.org/ 10.1175/JAMC-D-16-0164.1. 
Derin, Y., and K. K. Yilmaz, 2014: Evaluation of multiple satellite-based precipitation products over complex topography. J. Hydrometeor., 15, 1498-1516, https://doi.org/ 10.1175/JHM-D-13-0191.1.

_ , and Coauthors, 2016: Multiregional satellite precipitation products evaluation over complex terrain. J. Hydrometeor., 17, 1817-1836, https://doi.org/10.1175/JHM-D-15-0197.1.

French, M. M., D. Burgess, E. R. Mansell, and L. Wicker, 2015: Bulk hook echo raindrop sizes retrieved using mobile, polarimatric Doppler radar observations. J. Appl. Meteor. Climatol., 54, 423-450, https://doi.org/10.1175/JAMC-D-14-0171.1.

Gochis, D., and Coauthors, 2015: The great Colorado flood of September 2013. Bull. Amer. Meteor. Soc., 96, 1461-1487, https://doi.org/10.1175/BAMS-D-13-00241.1.

Gorgucci, E., V. Chandrasekar, and L. Baldini, 2008: Microphysical retrievals from dual-polarization radar measurements at $\mathrm{X}$ band. J. Atmos. Oceanic Technol., 25, 729-741, https://doi.org/ 10.1175/2007JTECHA971.1.

Grams, H. M., J. Zhang, and K. L. Elmore, 2014: Automated identification of enhanced rainfall rates using the near-storm environment for radar precipitation estimates. J. Hydrometeor., 15, 1238-1254, https://doi.org/10.1175/JHM-D-13-042.1.

Hamada, A., Y. N. Takayabu, C. Liu, and E. J. Zipser, 2015: Weak linkage between the heaviest rainfall and tallest storms. Nat. Commun., 6, 6213, https://doi.org/10.1038/ncomms7213.

Hou, A. Y., and Coauthors, 2014: The Global Precipitation Measurement Mission. Bull. Amer. Meteor. Soc., 95, 701-722, https://doi.org/10.1175/BAMS-D-13-00164.1.

Illingworth, A. J., and T. M. Blackman, 2002: The need to represent raindrop size spectra as normalized gamma distributions for the interpretation of polarization radar observations. J. Appl. Meteor., 41, 286-297, https://doi.org/10.1175/1520-0450(2002)041<0286: TNTRRS $>2.0 . C O ; 2$.

IPCC, 2014: Summary for policymakers. Climate Change 2014: Impacts, Adaptation, and Vulnerability. Part A: Global and Sectoral Aspects, C. B. Field et al., Eds., Cambridge University Press, 1-32.

Kalogiros, J., M. N. Anagnostou, E. N. Anagnostou, M. Montopoli, E. Picciotti, and F. S. Marzano, 2013: Optimum estimation of rain microphysical parameters from X-band dual-polarization radar observables. IEEE Trans. Geosci. Remote Sens., 51, 3063-3076, https://doi.org/10.1109/TGRS.2012.2211606.

,,,,---- and,- 2014 : Evaluation of a new polarimetric algorithm for rain-path attenuation correction of $\mathrm{X}$-band radar observations against disdrometer. IEEE Trans. Geosci. Remote Sens., 52, 1369-1380, https://doi.org/10.1109/ TGRS.2013.2250979.

Kirstetter, P.-E., Y. Hong, J. J. Gourley, M. Schwaller, W. Petersen, and Q. Cao, 2015: Impact of sub-pixel rainfall variability on spaceborne precipitation estimation: Evaluating the TRMM 2A25 product. Quart. J. Roy. Meteor. Soc., 141, 953-966, https://doi.org/10.1002/qj.2416.

Kumjian, M. R., 2011: Precipitation properties of supercell hook echoes. Electron. J. Severe Storms Meteor., 6, 1-21.

, and A. V. Ryzhkov, 2010: The impact of evaporation on polarimetric characteristics of rain: Theoretical model and practical implications. J. Appl. Meteor. Climatol., 49, 1247-1267, https://doi.org/10.1175/2010JAMC2243.1.

_, and _ 2012: The impact of size sorting on the polarimetric radar variables. J. Atmos. Sci., 69, 2042-2060, https://doi.org/ 10.1175/JAS-D-11-0125.1.

, and O. P. Prat, 2014: The impact of raindrop collisional processes on the polarimetric radar variables. J. Atmos. Sci., 71, 3052-3067, https://doi.org/10.1175/JAS-D-13-0357.1.
—, A. V. Ryzhkov, S. Trömel, M. Diederich, K. Mühlbauer, and C. Simmer, 2012: Retrievals of warm-rain microphysics using Xband polarimetric radar data. 26th Conf. on Hydrology, New Orleans, LA, Amer. Meteor. Soc., 406, https://ams.confex.com/ ams/92Annual/webprogram/Paper206846.html.

Lau, K. M., and H. T. Wu, 2003: Warm rain processes over tropical oceans and climate implications. Geophys. Res. Lett., 30, 2290 , https://doi.org/10.1029/2003GL018567.

Lebel, T., G. Bastin, C. Obled, and J. D. Creutin, 1987: On the accuracy of areal rainfall estimation: A case study. Water Resour. Res., 23, 2123-2134, https://doi.org/10.1029/ WR023i011p02123.

Liu, C., and E. J. Zipser, 2009: "Warm rain" in the tropics: Seasonal and regional distributions based on $9 \mathrm{yr}$ of TRMM data. J. Climate, 22, 767-779, https://doi.org/10.1175/ 2008JCLI2641.1.

Maddox, R. A., J. Zhang, J. J. Gourley, and K. W. Howard, 2002: Weather radar coverage over the contiguous United States. Wea. Forecasting, 17, 927-934, https://doi.org/ 10.1175/1520-0434(2002)017<0927:WRCOTC>2.0.CO;2.

Maggioni, V., P. C. Meyers, and M. D. Robinson, 2016: A review of merged high-resolution satellite precipitation product accuracy during the Tropical Rainfall Measuring Mission (TRMM) era. J. Hydrometeor., 17, 1101-1117, https://doi.org/ 10.1175/JHM-D-15-0190.1.

Mei, Y., E. N. Anagnostou, E. I. Nikolopoulos, and M. Borga, 2014: Error analysis of satellite precipitation products in mountainous basins. J. Hydrometeor., 15, 1778-1793, https://doi.org/ 10.1175/JHM-D-13-0194.1.

NOAA, 2015: Weather fatalities. NOAA/NWS, accessed 3 October 2016, http://www.nws.noaa.gov/om/hazstats.shtml.

Park, S., M. Maki, K. Iwanami, V. N. Bringi, and V. Chandrasekar, 2005: Correction of radar reflectivity and differential reflectivity for rain attenuation at X-band. Part II: Evaluation and application. J. Atmos. Oceanic Technol., 22, 1633-1655, https://doi.org/10.1175/JTECH1804.1.

Petersen, W. A., and Coauthors, 1999: Mesoscale and radar observations of the Fort Collins flash flood of 28 July 1997. Bull. Amer. Meteor. Soc., 80, 191-216, https://doi.org/10.1175/ 1520-0477(1999)080<0191:MAROOT>2.0.CO;2.

Ryzhkov, A. V., and D. Zrnić, 2005: Radar polarimetry at S, C, and X bands: Comparative analysis and operational implications. 32nd Conf. on Radar Meteorology, Albuquerque, NM, Amer. Meteor. Soc., 9R.3, https://ams.confex.com/ams/pdfpapers/95684.pdf. , S. E. Giangrande, and T. J. Schuur, 2005: Rainfall estimation with a polarimetric prototype of WSR-88D. J. Appl. Meteor., 44, 502-515, https://doi.org/10.1175/JAM2213.1.

Squires, P., 1956: The micro-structure of cumuli in maritime and continental air. Tellus, 8, 443-444, https://doi.org/10.3402/ tellusa.v8i4.9040.

Stoelinga, M. T., R. E. Stewart, G. Thompson, and J. M. Thériault, 2013: Microphysical processes within winter orographic cloud and precipitation systems. Mountain Weather Research and Forecasting, F. K. Chow, S. F. J. De Wekker, and B. J. Snyder, Eds., Springer, 345-408.

Vitale, J. D., and T. Ryan, 2013: Operational recognition of high precipitation efficiency and low-echo-centroid convection. J. Oper. Meteor., 1, 128-143, https://doi.org/10.15191/ nwajom.2013.0112.

Ward, E., W. Buytaert, L. Peaver, and H. Wheater, 2011: Evaluation of precipitation products over complex mountainous terrain: A water resources perspective. Adv. Water Resour., 34, 1222-1231, https://doi.org/10.1016/j.advwatres.2011.05.007. 
Warner, T. T., E. A. Brandes, J. Sun, D. N. Yates, and C. K. Mueller, 2000: Prediction of a flash flood in complex terrain. Part I: A comparison of rainfall estimates from radar, and very short range rainfall simulations from a dynamic model and an automated algorithmic system. J. Appl. Meteor., 39, 797-814, https://doi.org/ 10.1175/1520-0450(2000)039<0797:POAFFI >2.0.CO;2.

Xu, X., K. Howard, and J. Zhang, 2008: An automated radar technique for the identification of tropical precipitation. J. Hydrometeor., 9, 885-902, https://doi.org/10.1175/2007JHM954.1.

Zhang, G., J. Sun, and E. A. Brandes, 2006: Improving parameterization of rain microphysics with disdrometer and radar observations. J. Atmos. Sci., 63, 1273-1290, https://doi.org/ 10.1175/JAS3680.1.

Zhang, J., Y. Qi, D. Kingsmill, and K. Howard, 2012: Radar-based quantitative precipitation estimation for the cool season in complex terrain: Case studies from the NOAA Hydrometeorology Testbed. J. Hydrometeor., 13, 1836-1854, https://doi.org/ 10.1175/JHM-D-11-0145.1.
, C. Langston, B. Kaney, and K. Howard, 2014: A realtime algorithm for merging radar QPEs with rain gauge observations and orographic precipitation climatology. J. Hydrometeor., 15, 1794-1809, https://doi.org/10.1175/ JHM-D-13-0163.1.

— , and Coauthors, 2016: Multi-Radar Multi-Sensor (MRMS) quantitative precipitation estimation: Initial operating capabilities. Bull. Amer. Meteor. Soc., 97, 621-638, https://doi.org/ 10.1175/BAMS-D-14-00174.1.

Zrnić, D. S., and A. V. Ryzhkov, 1999: Polarimetry for weather surveillance radars. Bull. Amer. Meteor. Soc., 80, 389-406, https://doi.org/10.1175/1520-0477(1999)080<0389: PFWSR $>2.0 . \mathrm{CO} ; 2$.

Zwiebel, J., J. Van Baelen, S. Anquetin, Y. Pointin, and B. Boudevillain, 2016: Impacts of orography and rain intensity on rainfall structure. The case of the HyMeX IOP7a event. Quart. J. Roy. Meteor. Soc., 142, 310-319, https://doi.org/ 10.1002/qj.2679. 